\title{
AGRESIVITAS PAJAK DAN KINERJA LINGKUNGAN TERHADAP CORPORATE SOCIAL RESPONSIBILITY DISCLOSURE
}

\author{
Abid Ramadhan1*, Arfan Amrin2* \\ Program Studi Akuntansi, Fakultas Ekonomi dan Bisnis, Universitas Muhammadiyah \\ Palopo* Jl. Jend. Sudirman Km. 3 Binturu, Palopo 91922, Indonesia \\ E-mail: abidramadhan8@gmail.com ${ }^{1}$ \\ E-mail: amrin.arfan021090@gmail.com²
}

\begin{abstract}
Abstrak
Sejak kehadiran CSR di Indonesia mulai tahun 1980 hingga saat ini, efektivitas dan efesiensi pengelolaan dana CSR masih terdapat banyak kekurangan dalam pelaksanaannya. Hal ini disebabkan karena motivasi pengungkapan CSR di Indonesia diduga hanya untuk menjaga reputasi baik bagi pemegang saham. Selain itu, kehadiran UU No. 40 Tahun 2007 tentang kewajiban Perseroan Terbatas (PT), perusahan dinilai hanya sekedar mematuhi peraturan pemerintah tersebut. Tujuan dalam penelitian ini adalah untuk menguji pengaruh Agresivitas Pajak dan Kinerja Lingkungan sebagai variable independen dan CSR sebagai variabel dependen. Populasi sekaligus sampel pada penelitian ini berasal dari beberapa perusahaan yang terdaftar di JII (Jakarta Islamic Index) selama periode 2013 hingga 2017. Teknik pengumpulan data sampel menggunakan metode purposive sampling. Data dianalisis melalui analisis regresi linear berganda untuk mengetahui pengaruh antara variabel independen terhadap dependen. Hasil penelitian ini menunjukkan variabel Agresivitas Pajak tidak berpengaruh terhadap CSR. Sedangkan Kinerja Lingkungan berpengaruh terhadap CSR.
\end{abstract}

\section{Kata Kunci: Agresivitas Pajak, Kinerja Lingkungan dan CSR}

\begin{abstract}
Since the presence of CSR in Indonesia form 1980 until now, the effectiveness and effeciency of managing CSR funds are still lacking in its implementations. That is because a motivation about CSR in Indonesia is allegedly simply to maintain of good reputation for stakeholders. In additon, the precence of laws and regulation number 40 of 2007 regarding limited companies, companies be expected just obey with these government regulations. This study aims to examine atax aggressiveness and environmental performance as an independent variable on CSR as a dependent variable. The population and sample in this study from companies registered in Jakarta Islamic Index (JII) during 2013-2017 period. Sample data collection techniques using purposive sampling method. Data were analyzed through multiple linear regression analysis to determine the effect of independent variables on the dependent. The results of this study indicate the variable Tax Aggressiveness does not affect CSR, while Environmental Performance is related to CSR.
\end{abstract}

Key Word: Tax Aggressiveness, Environmental Performance, and CS 


\section{Pendahuluan}

CSR (Corporate Social Responsibility) adalah proses pelaporan perusahaan yang bertujuan untuk mengkomunikasikan dampak sosial maupun lingkungan yang timbul dari aktivitas ekonomi perusahaan pada suatu kelompok yang berkepentingan secara khusus dan masyarakat secara umum (Sembiring 2005).

Tujuan utama CSR diterapkan di perusahaanperusahaan adalah untuk menciptakan standar kehidupan yang lebih harmonis sebagai upaya mencegah terjadinya distrust atau ketidakpercayaan masyarakat terhadap kegiatan usaha perusahaan. Selain itu perusahaan yang menerapkan CSR berupaya untuk mempertahankan kesinambungan laba usaha untuk pemangku kepentingan dengan cara menyajikan laporan keuangan yang merupakan alat bagi perusahaan untuk melaporakan kegiatankegiatan yang telah dan akan dilakukan serta memberikan informasi-informasi yang mengandung pengungkapan-pengungkapan yang salah satunya adalah CSR disclosure (Kamil and Herusetya 2012).

Penelitian ini berusaha untuk menilai apa saja faktorfaktor yang dapat memberikan pengaruh terhadap CSR disclosure. Pada pembahasan kali ini, salah satu faktor yang dapat memberikan pengaruh terhadap CSR disclosure adalah AP (Agresivitas Pajak). Menurut Balakrishnan, et al (2011) bahwa agresivitas pajak merupakan keterlibatan perusahaan dalam segala macam perencanaan pajak sebaga upaya perusahaan untuk memperkecil/mengurangi kewajiban pajak yang telah ditentukan. Sehingga tindakan sebagai upaya dalam hal meminimalkan kewajiban pajak yang ditanggung perusahaan agar perusahaan memperoleh keuntungan lebih besar.

Beberapa kasus terjadi mengenai bidang perpajakan seperti kasus BHP Ltd, James Hardie Ltd dan News Corporation Ltd (Lanis dan Richardson 2013). Di Indonesia kasus pada Real Estate Indonesia (REI) yang dituduh oleh Direktorat Jenderal (Ditjen) Pajak terkait dokumen transaksi pembayaran pajak yang di duga banyak melakukan penghindaran pembayaran Pajak Penghasilan. Juga pada perusahaan pertambangan PT Bumi Resources Tbk, PT Kaltim Prima Coal (KPC), dan PT Arutmin Indonesia yang diduga oleh Ditjen Pajak melakukan manipulasi pajak pada tahun 2007 sebesar Rp2,1 triliun. Berdasarkan beberapa kasus di atas, tindakan agresivitas pajak dan tindakan mengabaikan CSR tentu akan merugikan pemerintah. Seharusnya warga negara taat membayar pajak dalam rangka menjalankan kewajiban negara, baik wajib pajak orang pribadi maupun badan hukum.

Penelitian yang dilakukan oleh A.P \& Hardiningsih, (2015) memberikan hasil bahwa variabel agresivitas pajak memiliki pengaruh terhadap CSR disclosure. Namun hasil penelitian lainnya sebagaimana hasil penelitian Octaviana \& Rohman, (2014) menunjukkan bahwa variabel agresivitas pajak tidak memiliki pengaruh terhadap CSR disclosure.

Selain variabel agresivitas pajak, variabel lainnya juga dapat memberikan pengaruh terhadap CSR disclosure yaitu variabel KL (kinerja lingkungan). Secara umum, kinerja lingkungan diukur dengan menggunakan pemeringkatan kinerja PROPER yang merupakan program dari kementrian lingkungan hidup yang menggunakan Lima warna yang berbeda sebagai alat ukurnya, diantaranya warna emas, hijau, biru, merah dan hitam. Di Indonesia sendiri, kelestarian lingkungan sudah menjadi kebijakan pemerintah pada setiap periode. Pada Pelita ketujuh melalui TAP MPR No. II/MPR/1998 tentang GBHN, dinyatakan: "Kebijakan Sektor Lingkungan Hidup, antara lain, mengenai pembangunan lingkungan hidup diarahkan agar lingkungan hidup tetap berfungsi sebagai pendukung dan penyangga ekosistem kehidupan dan terwujudnya keseimbangan, keselarasan dan keserasian yang dinamis antara sistem ekologi, sosial ekonomi, dan sosial budaya agar dapat menjamin pembangunan nasional yang berkelanjutan" (GBHN, 1998).

Beberapa penelitian telah menunjukkan hasil seperti penelitian Devita, (2015) yang memberikan hasil 
bahwa kinerja lingkungan memiliki pengarub. Perusahaan mempublikasikan laporan keuangan terhadap CSR disclosure. Sedangkan hasil penelitian secara lengkap yang berakhir pada 31 desember.

sebagaimana dilakukan oleh Oktalia, (2014x. Perusahaan menerbitkan annual report/laporan memberikan hasil bahwa kinerja lingkungan tidak memiliki pengaruh terhadap CSR disclosure. tahunan secara konsisten selama 5 tahun dari tahun 2013 hingga 2017.

Dengan adanya research gap diantara para peneliti Data penelitian yang diteliti berjumlah 150 sampel diatas dan beberapa kasus mengenai pengurangan pajak serta urgensi menjaga kelestarian lingkungan, maka peneliti tertarik melakukan penelitian ini. Selain itu, peneliti menilai bahwa sejauh kehadiran CSR di Indonesia mulai tahun 1980 - an hingga saat ini, masih terdapat banyak kekurangan dalam pelaksanaannya. Hal ini disebabkan karena motivasi pengungkapan CSR di Indonesia hanya untuk menjaga reputasi baik bagi pemegang saham.Selain itu, kehadiran UU No. 40 tahun 2007 mengenai kewajiban perseroan terbatas (PT), perusahan dinilai hanya sekedar mematuhi peraturan pemerintah tersebut.

\section{Metode Penelitian}

Penelitian ini bersifat kuantitatif dengan menggunakan angka numerik. Sumber data berasal dari data sekunder melalui observasi laporan tahunan perusahaan (annual report) untuk perusahaan yang listing di Jakarta Islamic Index (JII).

Populasi berasal dari daftar perusahaan-perusahaan yang listing di Jakarta Islamic Index (JII) dengan waktu observasi 5 tahun yakni 2013 hingga 2017. Sampel berasal dari perusahaan yang menerbitkan laporan tahunannya secara konsisten selama masa observasi. Jumlah data yang tersedia berjumlah 60 sampel dari tahap selanjutnya adalah mengambil sampel penelitian dengan teknik purposive sampling atau pengambilan sampel non-random yang dimana peneliti telah menetapkan cara pengambilan sampel dengan menggunakan ciri-ciri khusus yang seusai dengan tujuan penelitian. Berikut ini kriteria dari sampel penelitian:

a. Perusahaan menggunakan nilai mata uang rupiah dalam laporan keuangannya 
Penelitian ini menggunakan metode analisis regresi berganda (Multiple Regressions) sebagai upaya untuk menjawab berbagai masalah penelitian. Analisis regresi pada umumnya merupakan studi mengenai ketergantungan antara variabel dependen (terikat) dengan variabel independen (bebas) dengan tujuan memberikan perkiraan/prediksi mengenai rata-rata populasi atau nilai dari variabel dependen yang berasal dari nilai variabel independen yang telah diketahui. (Ghozali 2011).

Uji regresi digunakan dalam penelitian ini untuk memberikan jawaban apakah ada pengaruh variabel independen yakni Agresivitas Pajak (AP), Kinerja Lingkungan (KL) terhadap variabel dependen yakni pengungkapan CSR. Penelitian ini menggunakan pengujian hipotesis.Uji hipotesis adalah pengujian statistik penelitian untuk memperolah hasil yang diterima atau ditolak dari hipotesis penelitian.Uji hipotesis dapat dilakukan melalui uji $t$ parsial (sendiri).Uji t berfungsi untuk memberikan informasi tentang seberapa besar pengaruh suatu variabel independen (bebas) secara individu dalam menerangkan variasi variabel dependen (terikat). Tingkat (sig) adalah 5\% atau 0, 05. Berikut ini perumusan hipotesis:

$\mathrm{H}_{0} ; \beta 1=0 ; \beta 2=0 ; \beta 3=0$

$\mathrm{H}_{\mathrm{a}} ; \beta 1 \neq 0 ; \beta 2 \neq 0 ; \beta 3 \neq 0$

Kriteria yakni:

Jika nilai (sig) > 0, 05 maka $\mathrm{H}_{0}$ gagal ditolak

Jika nilai $\left(\right.$ sig) $<0,05$ maka $\mathrm{H}_{1}$ diterima

Rumus pengujian sebagai berikut :

$\mathrm{CSR}=\alpha+\beta_{1} \mathrm{AP}+\beta_{2} \mathrm{KL}+\mathrm{e}$

Dimana:

$\begin{array}{ll}\text { CSR } & \text { : corporate social responsibility disclosure } \\ \text { A } & \text { : constant } \\ \text { AP } & \text { : agresivitas pajak } \\ \text { KL } & \text { : kinerja lingkungan } \\ \text { B1- } \beta 3 & \text { : koefisien regressions } \\ \text { E } & : \text { Error }\end{array}$

\section{Analisis dan Pembahasan}

TABEL 2

\begin{tabular}{c|c|c|c|c|c}
\hline \multicolumn{7}{|c}{ STATISTIK DESKRIPTIF } \\
& $\mathrm{N}$ & $\begin{array}{l}\text { Mini } \\
\text { mum }\end{array}$ & $\begin{array}{c}\text { Maxi } \\
\text { mum }\end{array}$ & Mean & $\begin{array}{c}\text { Std. } \\
\text { Deviations }\end{array}$ \\
\hline
\end{tabular}

\begin{tabular}{l|l|l|l|l|l}
\hline CSR & 60 & 0,22 & 0,57 & 0,3703 & 0,08107 \\
Agresivit & 60 & 0,00 & 0,86 & 0,2302 & 0,11431 \\
as Pajak & 60 & 1,00 & 5,00 & 2,5000 & 1,28221 \\
Kinerja & & & & & \\
Lingkung & & & & & \\
an & & & & & \\
Valid N & & & & & \\
(Listwise & & & & & \\
) & & & & & \\
\hline
\end{tabular}

Berdasarkan pada tabel 2, dapat diketahui bahwa nilai untuk CSR berada pada nilai antara 0.22 hingga 0,57. CSR terendah berasal dari PT. Bumi Serpong Damai. Tbk dan tertinggi dimiliki oleh PT. Semen Indonesia.Tbk.

Berdasarkan pada tabel diatas,dapat diketahui bahwa nilai untukAgresivitas Pajak yang diukur menggunakan Efective Tax Rate (ETR) berkisar antara 0,00 hingga 0,86. ETR terendah berasal dari PT. Bumi Serpong Damai.Tbk dan tertinggi dimiliki oleh PT. Indofood CBP Sukses Makmur Tbk.

Berdasarkan hasil perhitungan pada tabel 2, dapat diketahui bahwa nilai Kinerja Lingkungan berada pada nilai antara 1.00 hingga 5, 00. Nilai PROPER terendah berasal dari PT. Astra International.Tbk dan tertinggi dimiliki oleh PT. Unilever Indonesia.Tbk

TABEL 3

UJI DETERMINASI (R2)

\begin{tabular}{|c|c|c|c|c|}
\hline & & $\mathrm{R}$ & $\begin{array}{c}\text { Adju } \\
\text { sted } \\
\mathrm{R}\end{array}$ & $\begin{array}{c}\text { Std. } \\
\text { Error of } \\
\text { the } \\
\text { Model }\end{array}$ \\
\hline 1 & $\mathrm{R}$ & $\begin{array}{c}\text { Squar } \\
\mathrm{e}\end{array}$ & $\begin{array}{c}\text { Squa } \\
\text { re }\end{array}$ & $\begin{array}{c}\text { estimat } \\
\mathrm{e}\end{array}$ \\
\hline 1 & 0,327 & 0,107 & $\begin{array}{c}0,07 \\
5\end{array}$ & 0,07794 \\
\hline
\end{tabular}

Pada tabel 3 diatas, nilai koefisiensi determinasi $\left(\mathrm{R}^{2}\right)$ menunjukkan seberapa erat hubungan variabel indepeden (bebas) yakni Agresivitas Pajak (AP), Kinerja Lingkungan (KL) dengan variabel dependen (terikat) yakni CSR Dislosure.Nilai $\mathrm{R}^{2}$ adalah 0,327 yang menunjukkan adanya hubungan variabel Agresivitas Pajak (AP), Kinerja Lingkungan (KL) dengan variabel Pengungkapan Corporate Social Responsibility (CSR) memiliki hubungan yang cukup erat atau kuat. Nilai $\mathrm{R}^{2}$ sebesar 0,107 atau sebesar 10,7\% yang berarti CSR Disclosure dapat dijelaskan oleh variabel Agresivitas Pajak (AP), Kinerja Lingkungan (KL) sebesar nilai tersebut sedangkan 
sisanya sebesar $89,3 \%$ berasal dari pengaruh lain dilur model yang telah diteliti.

TABEL 4

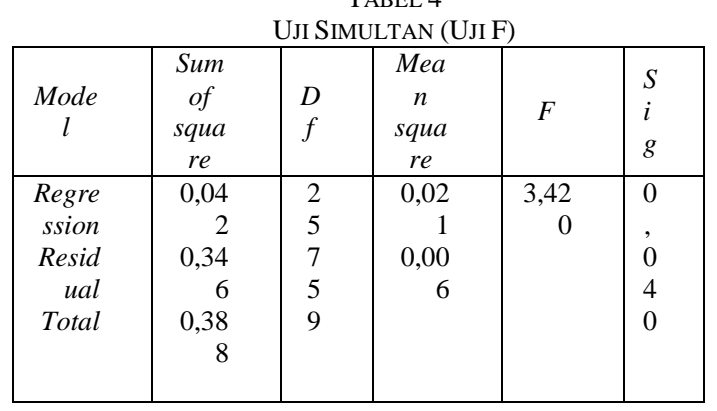

Pada tabel 4 diatas menunjukkan hasil bahwa statistik uji $F_{\text {hitung }}=3,420$ dengan nilai signifikan 0,040 < 0 , 05 atau $\alpha=5 \%$. Hal tersebut menunjukkan bahwa $\mathrm{H}_{0}$ diterima.Oleh karena itu, dapat diambil kesimpulan bahwa variabel independen yakni Agresivitas Pajak (AP), Kinerja Lingkungan (KL) dapat mempengaruhi variabel dependen yakni CSR disclosure secara simultan/bersama-sama.

TABEL 5 UJI PARSIAL (UJI T)

\begin{tabular}{l|c|c|c|c|c}
\hline \multirow{2}{*}{ Model } & \multicolumn{2}{|c|}{$\begin{array}{c}\text { Unstandarized } \\
\text { Coefficients }\end{array}$} & $\begin{array}{c}\text { standar } \\
\text { ized } \\
\text { Coeffic } \\
\text { ients }\end{array}$ & $\mathrm{t}$ & Sig \\
\cline { 2 - 4 } & $\mathrm{B}$ & $\begin{array}{c}\text { Std. } \\
\text { Error }\end{array}$ & Beta & & \\
\hline (Costant) & 0,328 & 0,026 & & 12,531 & 0,000 \\
agresivita & $-0,055$ & 0,096 & $-0,077$ & $-0,566$ & 0,573 \\
S pajak & 0,022 & 0,009 & 0,350 & 2,573 & 0,013 \\
$\begin{array}{l}\text { Kinerja } \\
\text { Lingkung } \\
\text { an }\end{array}$ & & & & & \\
\hline
\end{tabular}

Pada tabel 5 diatas menunjukkan bahwa Uji t berfungsi untuk memberikan informasi ada atau tidaknya pengaruh variabel independen (bebas) secara parsial/sendiri terhadap variabel dependen (terikat). Berikut ini perumusan hipotesis:

a. $\mathrm{H}_{0}=$ variabel independen tidak berpengaruh secara parsial/sendiri terhadap variabel dependen

b. $\mathrm{H}_{1}=$ variabel independen berpengaruh secara parsial/sendiri terhadap variabel dependen

c. Taraf nyata $(\alpha)$ yang digunakan dalam penelitian ini adalah $\alpha=5 \%$ atau 0,05 dengan asumsi bahwa tingkat pengaruh uji sebesar 95\% dari keseluruhan 60 sampel yang diteliti.

\section{Pembahasan}

\section{H1: AP (Agresivitas Pajak) tidak memiliki pengaruh terhadap CSR disclosure}

Berdasarkan pada tabel 6 , besarnya nilai $t_{\text {hitung variabel }}$ AP (Agresivitas Pajak) yakni-0,566dengan nilai (sig) signifikansi 0,573. Artinya nilai tersebut (sig) $t_{\text {hitung }}>$ 0,05 (diasumsikan lebih besar dari $\alpha=5 \%$ ). Hasil tersebut memberikan penjelasan atau makna $\mathrm{H}_{0}$ gagal ditolakkemudian $\mathrm{H}_{1}$ ditolak. Oleh karena itu, AP (Agresivitas Pajak) tidak memiliki pengaruh terhadap CSR disclosure.

\section{H2: KL (Kinerja lingkungan) memiliki pengaruh terhadap CSR disclosure}

Pada tabel 6 diatas, besarnya nilai thitung variabel KL (kinerja lingkungan) yakni 2,573 dengan nilai (sig) signifikansi 0,013. Artinya nilai (sig) signifikansi $t_{\text {hitung }}<$ 0,05 (diasumsikan lebih kecil dari $\alpha=5 \%$ ). Hasil tersebut memberikan penjelasan bahwa $\mathrm{H}_{0}$ ditolak kemudian $\mathrm{H}_{1}$ gagal ditolak. Oleh karena itu, KL (kinerja lingkungan) memiliki pengaruh terhadap CSR dan hal ini mempertegas bahwa penelitian ini sejalan dengan tujuan dari TAP MPR No. II/MPR/1998 tentang GBHN dalam upaya untuk menjaga ekosistem lingkungan hidup dan anjuran agar perusahaan dapat selaras dan sejalan dengan ekosistem sekitarnya.

\section{Simpulan dan Hasil}

Variabel kinerja lingkungan memiliki peran untuk dapat mempengaruhi calon investor atau sstakeholder's dalam melakukan investasi di perusahaan melebihi Agresivitas Pajak. Hal ini dibuktikan dengan pengujian regresi yang disajikan di atas bahwa tingkat signifikansi kinerja lingkungan $0,013<0.05$. Oleh karenanya, sangat penting bagi perusahaan untuk selalu menjaga tingkat PROFER tetap berada pada tingkat warna emas yakni 5 dan hijau yakni 4. Dalam penelitian ini terdapat beberapa keterbatasan, diantaranya yakni jumlah sampel dalam penelitian ini hanya berjumlah 60 perusahaan dan sampel dinyatakan memenuhi syarat sebagai data penelitian. Namun jumlah 
tersebut kurang maksimal dalam menjawab masalah penelitian. Selain itu, jumlah variabel yang digunakan berjumlah tiga variabel sehingga perlu kiranya untuk memperbanyak atau mencari variabel lain untuk menguji pengaruh CSR disclosure.

Untuk para peneliti selanjutnya yang berminat meneliti tentang CSR disclosure maka disarankan untuk menambah jumlah sampel penelitian dan memperluas observasi pencarian data serta menggunakan alat analisis lainnya guna memperolah hasil yang lebih maksimal.

\section{DAFTAR PUSTAKA}

A.P, Winda Plorensia, and Pancawati Hardiningsih. 2015. "Pengaruh Agresivitas Pajak Danmedia Eksplosure Terhadap Corporate Social Responsibility." Dinamika Akuntansi, Keuangan dan Perbankan 4(2): 136-51.

Balakrishnan, Karthik, Jennifer L. Blouin, and Wayne R. Guay. 2011. "Does Tax Aggressiveness Reduce Financial Reporting Transparency?" SSRN Electronic Journal (215). http://www.ssrn.com/abstract=1792783.

Devita, Endah Yola. 2015. "Pengaruh Kinerja Lingkungan Terhadap Luas Pengungkapan Corporate Social Responsibility Dimoderasi Oleh Debt to Equity Ratio (DER) (Studi Empiris Pada Perusahaan Manufaktur Yang Terdaftar Di BEI 2011, 2012, Dan 2013)." Jom FEKON 2(2): 1-15.

Elma Octaviana, Natasya, and Abdul Rohman. 2014
"Pengaruh Agresivitas Pajak Terhadap Corporate Social Responsibility: Untuk Menguji Teori Legistimasi." Diponegoro Journal of Accounting 03(02): 1-12. http://ejournals1.undip.ac.id/index.php/accounting.

Ghozali, Imam. 2011. Aplikasi Analisis Multivariate Dengan Program SPSS. Semarang: Badan Penerbit Universitas Diponegoro.

Haniffa, Ros. 2002. "Social Reporting Disclosure: An Islamic Perspective." Indonesia Manahement \& Accounting Research 1(2): 128-46.

Kamil, Ahmad, and Antonius Herusetya. 2012. "Pengaruh Karakteristik Perusahaan Terhadap Luas Pengungkapan Kegiatan Corporate Social Responsibility." media riset akuntansi 2(1):1-17. http://jurnal.bakrie.ac.id/index.php/journal_MRA/articl e/viewFile/43/32.

Lanis, Roman, and Grant Richardson. 2013. "Corporate Social Responsibility and Tax Aggressiveness: A Test of Legitimacy Theory." Accounting, Auditing and Accountability Journal 26(1): 75-100.

Oktalia, Dwi. 2014. "Pengaruh Kinerja Lingkungan Dan Profitabilitas Terhadap Corporate Social Responsibility Disclosure Dalam Laporan Tahunan Perusahaan." : 126.

Sembiring, Eddy Rismanda. 2005. "Karakteristik Perusahaan Dan Pengungkapan Tanggung Jawab Sosial: Studi Empiris Pada Perusahaan Yang Tercatat Di Bursa Efek Jakarta." Simposium Nasional Akuntansi XVI (September): 379-95.

www.idx.co.id

www.globalreporting.org 